\title{
The Relationship between Locus of Control and Perceived Stress
}

\author{
Vedavati Paranjpe ${ }^{1}$ \\ ${ }^{1}$ Department of Psychology, Joshi-Bedekar College, Thane \\ E-mail -veda18985@gmail.com
}

\begin{abstract}
The concept of Locus of Control has been extensively researched with different correlates including health, achievements. Locus of Control and Stress has also been studied with different samples. The present research addressed the correlation between Locus of Control and Perceived Stress. It has been hypothesized that there is positive correlation between locus of control and stress. To measure locus of control of participants Rotter's Locus of Control Scale was used, whereas to measure stress Perceived Stress Scale by Sheldon Cohen was used. The research sample consisted of 100 lecturers working in junior and senior college. Results denoted a moderate positive correlation between locus of control and stress. Limitations of the research have been discussed.
\end{abstract}

Keywords: Locus of Control (LOC), Perceived Stress, Lecturers

\section{INTRODUCTION}

Stress can be defined as mental, physical and emotional reactions one experiences as a result of demands in presented by life circumstances. A number of factors can be identified as causes of stress. It can be caused by external circumstances or person's perceptions and attitudes. External circumstances include death of spouse or other family members, injury or illness of any family member, changing house or city, change of job, strained relationship with colleagues and so on. However, some of the personality dimensions can also lead to the experience of stress. One such cause is Type A personality, which is characterized by time urgency, hostility, aggression and competitiveness. Locus of Control is also one of the personality dimensions which may alter the person's experience of stress. The concept of Locus of Control was developed by Julian Rotter in 1954 [1]. The Locus of control refers to the extent to which individuals believe that they can control events that affect them [2]. One's locus can either be internal or external. Individuals with high Internal Locus of Control believe that events result primarily from their own behavior and actions. According to them they control their lives. Whereas, those with high external locus of control believe that their environment, some higher power, fate, chance or other people control their decisions and events in their life. Those with a more internal locus of control tend to feel happier, more free, and less stress. They also enjoy better health (likely because they experience less of the damaging chronic stress that can come from feeling powerless), and are more 
satisfied with life in general. Those with an external locus of control are more susceptible to depression as well as other health problems, and tend to keep themselves in situations where they will experience additional stress, feeling powerless to change their own circumstances, which just adds to their stress.

It is implied that life events are stressful when they are perceived to be uncontrollable [3]. This suggests, therefore, that people who are able to take control of their own lives, (hence people with an internal locus of control) tend to be less stressed. Other research shows that externals are less capable than internals on a variety of tasks. Externals favor tests of chance over tests of skill, as they believe any experience or achievement is attributable to luck or chance [4]. In the area of stress, Locus of Control is one of the construct which has been studied extensively. Locus of Control of the person may change the way in which the stressful life events or situations are interpreted and dealt with. People with internal locus of control may take immediate actions to reduce the stress and have confidence in their ability to deal with difficult situations. Whereas, those who have external locus of control may blame other people, luck or chance for the stressful life events and thus they rely more on external help and hope that things might change while becoming unable to take charge of situation. Researchers [5] found that internal locus of control moderated the relationship between stressful life events and illness among college students. Evidence also showed that internal locus of control alleviated emotional distress following a cancer diagnosis [6], and helped people to adapt successfully to stressful work settings [7]. Internal locus of control was strongly related to job performance [8] and job satisfaction [9]. In a metaanalysis [10] confirmed that locus of control is related to job strain, indicated by job satisfaction, symptoms and emotional distress.

Several researches have been carried out to examine the relation between some personality dimensions and stress perceived by individuals. A study [11] examined life stress and some personality variables by comparing samples of working women and housewives. This study investigated possible differences in life stress, anxiety and locus of control, Type A behavior and personal efficacy of working women and housewives. Data from 105 working women (lecturers, factory workers, nurses) and 75 housewives are analyzed. The Life Changes Experience Survey, State Trait Anxiety Inventory, Social Reaction Inventory, Jenkins Activity Survey and Personal Efficacy Scale were administered to the subjects. Statistics applied were coefficient of correlation, mean, SD and the test of the significance of the difference. The analysis identified a number of differences between working women and housewives regarding their life stress, statetrait anxiety, locus of control, type A behavior and personal efficacy. The differences were found to be significant beyond the 0.05 and 0.01 levels.

Review of literature shows that the concept of correlation between Locus of Control and Stress has also been studied extensively. The research done is mainly correlational in nature. A study examining the impact of locus of control on job stress, job performance and job satisfaction in Taiwan was done [12]. The research sample consisted of accounting professionals. The findings indicate that one aspect of an accountants' personality, as measured by locus of control, plays an important role in predicting in the level of job satisfaction, stress and performance in CPA firms in Taiwan. Individuals with a higher internal locus of control are more likely to have lower levels of job stress and higher levels of job performance and satisfaction. The results indicate that locus of control plays an important role in the overall effectiveness of accountants. 
Stress experienced by teachers related to their age, sex and locus of control was investigated. This study was designed to test the hypothesis that a feeling of being in control will make potentially stressful environmental events less so. Subjects were practicing teachers about who little was known regarding the relationship between locus of control and stress. They responded to the Teacher Locus of Control Scale and the Teacher Occupational Stress Factor Questionnaire. Multivariate and bivariate analyses of their responses showed that locus of control were related to teacher stress. As hypothesized, teachers who felt that they were in control reported less stress in their world of work than did those who did not feel influential in their educational environment. Neither sex nor age moderated this relationship [13].

In another study conducted [14], LOC and Stress were studied. The research was titled as Perceived Work Stress and Locus of Control: A Combined Quantitative and Qualitative Approach. This study set out to examine perceived work stressors of internals and externals, combining quantitative and qualitative analyses, as well as relationships between locus of control and a wide array of job strain indicators. A sample of 1,054 industrial workers in Taiwan was surveyed. Results showed that, compared with the internals, the externals tended to perceive more sources of stress; moreover, they reported more stressors, which seemed to be outside their direct control. On the other hand, internals were more satisfied with their jobs, suffered fewer physical and psychological symptoms, and exerted more coping efforts. The role of control was discussed in the context of the Chinese work settings. A field study [15] has tested the main effects of (1) locus of control and social support on job stress; of (2) stress, locus of control, and social support on strain; and of (3) of stress, locus of control, social support, and strain on propensity to leave a job. The study also tested the moderating effects of locus of control and social support on the stress-strain relationship. These effects were tested with questionnaire data collected from a random sample of 288 managers. Results from hierarchical regression analyses found general support for the effects related to locus of control but not social support. A major implication for the findings is that managers who possess high internal locus of control personality should be particularly selected for positions which involve high stress.

Moderating effects of locus of control on the relationship of occupational stress and job strain were investigated [16]. The concept of job strain included job dissatisfaction and job tension. Sample consisted of 200 bank professionals. It was observed that occupational stress significantly correlated with job satisfaction $(r=.-20)$ and job tension $(r=.17)$. The inverse relationship between occupational stress and job satisfaction was found to be buffered by internal locus of control and intensified by external locus of control.

The present study was conducted to see the relationship between Locus of Control and Perceived Stress of lecturers, teaching in junior and senior college. To measure the locus of control beliefs of lecturers, Rotter's Locus of Control Scale was used. Whereas, to measure the stress levels Perceived Stress Scale by Sheldon Cohen was used. Both of the questionnaires were administered on 100 lecturers of Thane. The following hypothesis was proposed that higher the locus of control of participants, higher is the perceived stress.

\section{METHODOLOGY}


The participants recruited for the study were selected randomly from a college of Thane, affiliated to Mumbai University. 100 lecturers were included in the study. Participation in the research was voluntary. In the present study two questionnaires were used in order to measure the two variables. Rotter's Locus of Control Scale was used to measure Locus of Control of participants and Sheldon Cohen's Perceived Stress Scale was used to measure the stress levels. The Locus of Control Scale was developed by Julian Rotter [1] which was used for finding the Locus of Control of participant. Locus of Control Scale is a forced choice, self report inventory. It has 29 pairs of statements in which there are 6 filler items. Each item has two statements a and $b$, among which the participant had to circle the one that he finds most applicable to himself. There is no time limit to solve this test. A separate scoring key is available to do scoring.

The Perceived Stress Scale is a 10-item self report questionnaire that measures persons' evaluation of the stressfulness of the situations in the past month of their lives. The Perceived Stress Scale measures subjective evaluations of the stressfulness of a situation. These are referred to as appraisals or perceptions of stress.

The Perceived Stress Scale is the only empirically established index of general stress appraisal. Internal reliability of the test was found to be Coefficient alpha of 0.78 [17]. Construct validity for PSS scores were moderately related to responses on other measures of appraised stress, as well as to measures of potential sources of stress as assessed by event frequency. In a study examining the relationship of the common cold to negative life events, negative affect, and perceived stress, having more negative life events was associated with more severe clinical illness (i.e., more severe symptoms) whereas greater negative affect and perceived stress were associated with a higher probability of becoming infected [18]. This demonstrates that perceived stress is not the same as negative life events themselves, even though it may have been the negative life events that contributed to the perceived stress.

Participants in this research consisted of 100 lecturers teaching in Joshi-Bedekar College, Thane, affiliated to Mumbai University. Those lecturers who voluntarily wanted to take part in the study were given both the test booklets one after the other. Before the conduction of the test for research purpose, all the participants were explained the reason for administration of the tests and assured of confidentiality. Thus consent was taken from the participants, keeping in mind ethical concern of informed consent. The instructions were read to the participants and they were told to answer the questions honestly. They were given sufficient time to complete both the questionnaires. The doubts raised by the participants were answered frankly. Upon completion of the survey, the participants were thanked for their cooperation.

\section{RESULTS}

The present research was done to find out the relationship between Locus of Control and Perceived Stress amongst lecturers. According to the hypothesis of the research, higher the locus of control of participants, higher is the perceived stress. The Product Moment Coefficient of Correlation or Pearson's correlation coefficient was calculated to find out the correlation between LOC and Perceived Stress. Table 1 consists of the scores of 100 participants for locus of control and perceived stress scale. Table 2 is summary data table for the calculation of Pearson's Correlation Coefficient. The 
correlation of coefficient was found to be 0.67 , which denotes moderate positive correlation, a substantial but small relationship between two variables.

Table 1: Table for Pearson Correlation Coefficient

\begin{tabular}{|l|l|l|l|}
\hline \multicolumn{2}{|c|}{} & \multicolumn{1}{|c|}{$\begin{array}{c}\text { Locus of } \\
\text { Control }\end{array}$} & \multicolumn{1}{|c|}{ Perceived Stress } \\
& & & \\
\hline $\begin{array}{l}\text { Locus of } \\
\text { Control }\end{array}$ & $\begin{array}{l}\text { Pearson } \\
\text { Correlation } \\
\text { Sig. (1-tailed) } \\
\text { N }\end{array}$ & 1 & $0.677^{* *}$ \\
\hline $\begin{array}{l}\text { Perceived } \\
\text { Stress }\end{array}$ & $\begin{array}{l}\text { Pearson } \\
\text { Correlation } \\
\text { Sig. (1-tailed) } \\
\text { N }\end{array}$ & $0.677^{* *}$ & $\begin{array}{l}0.000 \\
100\end{array}$ \\
\hline$* *$ Correlation is significant at the $\mathbf{0 . 0 1}$ level (1-tailed). \\
\hline
\end{tabular}

\section{DISCUSSION}

It was hypothesized that higher the locus of control of participants, higher is the perceived stress. The value of the product moment correlation of coefficient ( $r$ ) was found to be 0.67 , which is statistically significant at 0.01 level and denotes a moderate correlation, substantial but small relationship. Thus, there is moderate positive correlation between LOC and Perceived stress and the hypothesis of the research has been marginally validated by the obtained data. The results are in line with the existing literature in which the relationship between LOC and stress was demonstrated. Research conducted [12] suggests that individuals with a higher internal locus of control are more likely to have lower levels of job stress and higher levels of job performance and satisfaction. The study about stress experienced by teachers related to their age, sex and locus of control [13] shows the relationship between locus of control and stress. Multivariate and bivariate analyses in this study showed that locus of control were related to teacher stress. As hypothesized, teachers who felt that they were in control reported less stress in their world of work than did those who did not feel influential in their educational environment. Neither sex nor age moderated this relationship.

However, the correlational value found in the present study denotes a small though substantial relationship between locus of control and perceived stress amongst lecturers. A number of factors might explain these results. In various researches it has been shown that culture plays a major role in determining one's locus of control. In Indian culture, religiousness and spirituality prevails. Both of these attributed are inculcated and reinforced in many of the families. These attributes may lead to the strong belief on God (any other spiritual power) and as well to the trust that God will provide us support in difficult situations and we may rely on him. This belief, though 
indicative of external locus of control, may result in less stress and relaxed attitude towards life. The college from where the data of the research has been collected encourages various recreational activities apart from the work. It also conducts various workshops on life skills including stress management for its staff. The work culture is extremely healthy and values such as co-operation, organization and teamwork are practiced and encouraged. The college consists of a counseling cell, where the problems such as extreme stress are dealt with. These all factors naturally lead to a limited experience of stress.

The questionnaire used to measure stress is a small scale, consisting of 10 items. The scale might not be able to represent stress prevalent in all the areas of one's life adequately. Thus, a more comprehensive scale may depict more significant correlation between locus of control and stress. Personality traits apart from locus of control as well as environmental conditions may also play a role in determining level of stress.

The research findings could be implied in different ways, such as to design and develop a training program for lecturers which gives an outlook of Locus of Control concept and denotes the benefits of having Internal LOC, to continue and enhance conduction of various stress management and life skills training programs. Several limitations have to be taken into consideration while interpreting the results of present study. The research has not taken into consideration differences in age, gender and years of experience which might influence both the variables being studied. The research sample is not adequate to make generalizations. The scale used to measure stress does not aim to measure stress experienced in specific areas, but gives a general estimate of the stress levels. It was hypothesized that higher the locus of control of participants, higher is the perceived stress. From the obtained results it can be concluded that there is moderate positive correlation between locus of control and stress and the hypothesis of the study is marginally validated.

\section{REFERENCES}

1. Rotter JB. Social learning and clinical psychology. NY: Prentice-Hall ; 1954.

2. Lefcourt HM. Internal versus external control of reinforcement: A review. Psychol Bull 1976;65(4): 206-220.

3. Kobasa (2011 oct 26). Retrieved from www.123helpme.com

4. Kahle LR. Stimulus condition self-selection by males in the interaction of locus of control and skill-chance situations. J Personal Soc Psychol 1980;38(1):50-56.

5. Johnson JH, Sarason IG. Life stress, depression and anxiety: Internal-external control as a moderator variable. J Psychosom Res 1978;22(3):205-208.

6. Marks G, Richardson JL, Graham JW, Levine A. Role of health locus of control beliefs and expectations of treatment efficacy in adjustment to cancer. J Personal Soc Psychol $1986 ; 51(2): 443-447$.

7. Judge TA, Bono JE. Relationship of core self-evaluations traits-self-esteem, generalized self-efficacy, locus of control, and emotional stability-with job satisfaction and job performance: A meta-analysis. J Appl Psychol 2001;86(1):80.

8. Ng TW, Sorensen KL, Eby LT. Locus of control at work: a meta-analysis. J Organizat Behav 2006;27(8):1057-1087.

9. Lu L, Kao SF, Cooper CL, Spector PE. Managerial stress, locus of control, and job strain in Taiwan and UK: A comparative study. Int J Stress Manag 2000;7(3):209-226.

10. Storms PL, Spector PE. Relationships of organizational frustration with reported behavioural reactions: The moderating effect of locus of control. J Occup Psychol $1987 ; 60(3): 227-234$. 
11. Anderson CR. Locus of control, coping behaviors, and performance in a stress setting: a longitudinal study. J Appl Psychol 1977;62(4):446.

12. Chen JC, Silverthorne C. The impact of $<$ IT $>$ locus $</$ ITT $>$ of control on job stress, job performance and job satisfaction in Taiwan. Leadership Organiz Dev J 2008;29(7):572582.

13. Halpin G, Harris K, Halpin G. Teacher stress as related to locus of control, sex, and age. J Experiment Educn 1985;53(3):136-140.

14. Spector PE, Cooper CL, Sanchez JI, O'Driscoll M, Sparks K, Bernin P, Yu S. Locus of control and well-being at work: how generalizable are western findings?. Acad Manag J 2002;45(2):453-466.

15. Rahim MA. Relationships of stress, locus of control, and social support to psychiatric symptoms and propensity to leave a job: A field study with managers. J Business Psychol 1997;12(2):159-174.

16. Srivastava S. Locus of Control as a Moderator for Relationship between Organisational Role Stress and Managerial Effectiveness. Vision:The Journal of Business Perspective 2009;13(4):49-61.

17. Cohen S. Perceived stress in a probability sample of the United States. American Psychological Association; 1988.

18. Cohen S, Tyrrell DA, Smith AP. Negative life events, perceived stress, negative affect, and susceptibility to the common cold. J Personal Soc Psychol 1993;64(1):131-136.

Acknowledgements - Nil

Conflict of Interest - Nil

Funding - Nil 